\title{
16p11.2p12.2 microdeletion syndrome
}

INSERM

\section{Source}

INSERM. (1999). Orphanet: an online rare disease and orphan drug data base.

16p11.2p12.2 microdeletion syndrome. ORPHA:261211

16p11.2-p12.2 microdeletion syndrome is a recently described syndrome characterized by developmental delay and facial dysmorphism. 